\title{
The Effect of Environmental and Social Corporate Governance on the Financial Performance with Special Focus on the Egyptian Private Sector Companies within Egx30
}

\section{Mohamed A Elshawarby*}

Department of Accounting, High Institute of Computer Science and Information Systems, New Cairo Academy, Cairo, Egypt

\begin{abstract}
Egyptian private sector companies are face increasing pressure on two fronts-requiring greater transparency and disclosure and the need to apply good Environmental and Social Corporate Governance (ESCG) practices. The main objective of this research paper is to examine the relation between Environmental and Social Corporate Governance practices and financial performance (FP) of Egyptian private sector companies included in the official share index of the Egyptian stock change. EGX 30 index the index includes 30 largest firms where liquidity and action. The EGX 30 is weighted at market value and adjusted by free float. The adjusted market value of the listed company is the number of its shares multiplied by the closing price of that company multiplied by the percentage of shares offered freely. This study provides important evidence on the impact of ESCG performance on Corporate Financial Performance (CFP). "This is particularly important given this sustainability and ESCG performance to identify key business activities of listed companies in Egypt. The study concluded that there is a strong correlation between social governance with its four dimensions (board responsibilities, disclosure, and transparency and investor rights protection) and the financial performance of Egyptian private sector companies within EGX30.
\end{abstract}

Keywords: Environmental and Social Corporate Governance (ESCG); Financial performance; Egyptian private sector companies; EGX30

\section{Introduction}

In light of the global changes taking place in the business world today, especially with the development of societies that have put pressure on the institution to adjust its policy towards stakeholders, economic institutions cannot use discrimination in the process of creating value for certain parties at the expense of others because they are not important In her view, today's business world forces institutions to be more responsive than in the past in their social performance. The perception of stakeholders has taken on new and more complex dimensions, given the emergence of modern concepts that have helped to create a working environment capable of dealing with rapid global economic, technological and administrative developments.

There is still enough ambiguity and knowledge on the part of individuals, corporations and society as a whole on the concept of ESCG of the Egyptian private sector companies, their dimensions and their development, as well as their effectiveness, development and use. In light of this, the paper raises the following questions:

1. What is meant by the Environmental and Social Corporate Governance Practices (ESCG) of the Egyptian private sector companies?

2. What is the historical development of this concept?

3. What are the lessons learned from international experiences in the field of ESCG of the Egyptian private sector companies?

4. What is the effect of ESCG practices on the financial performance (FP) of the Egyptian private sector companies?

This study contributes to the literature in several important ways. First, it provides a unique empirical guide that assesses the relationship between ESCG and financial performance (FP). There is a clear positive relationship. The results indicate that the company involved in governance ESCG activities is also a positive financial performance, confirming the view that governance ESCG is the primary activity used by companies to support their financial activities. Our findings support the view that ESCG activities maintain financial performance [1]

This study is the first to document this relationship empirically in Egypt. Second, this study expands literature by examining the relationship between ESCG and FP of Egyptian private sector companies within EGX30. This is particularly important given this sustainability and ESCG performance to identify key business activities of listed companies in Egypt.

\section{Problematic search}

One of the most important developments in the economic, technological and social environment is the growing awareness of individuals in all countries in different aspects of life. Institutions are facing a new challenge of growing pressure from interest groups, including consumers, requiring them to increase attention to ocean variables and to adopt ESCG to reduce practices which threaten the future of the institution in survival and continuity.

In the attempt to reconcile its commitments with the direction of the environment and to achieve an appropriate return on its investments, the problem of studying the extent to which Egyptian private sector companies are committed to the implementation of ESCG practices

*Corresponding author: Dr. Mohamed A Elshawarby, Associate Professor Department of Accounting, High Institute of Computer Science and Information Systems, New Cairo academy, Cairo, Egypt, Tel: +20663334491; E-mail: Ishwrby@yahoo.com

Received March 31, 2018; Accepted April 12, 2018; Published May 13, 2018

Citation: Elshawarby MA (2018) The Effect of Environmental and Social Corporate Governance on the Financial Performance with Special Focus on the Egyptian Private Sector Companies within Egx30. J Account Mark 7: 269. doi: 10.4172/2168 9601.1000269

Copyright: ( 2018 Elshawarby MA. This is an open-access article distributed under the terms of the Creative Commons Attribution License, which permits unrestricted use, distribution, and reproduction in any medium, provided the original author and source are credited. 
is described as their role in improving performance by answering the following questions:

1. What is the role of ESCG in improving financial performance and its impact on the market value of Egyptian private sector companies?

2. This question can be explained in more detail by a series of questions The sub-dimensions are related to the dimensions of ESCG practices as follows:

3. What is the role of ESCG practices (board responsibilities, disclosure and transparency, protecting shareholders' rights) in improving the financial performance of Egyptian private sector companies?

4. What is the impact of ESCG (responsibility towards the environment, responsibility towards consumers, and responsibility towards society) on the market value of private sector companies in Egypt?

We seek from this research to try to reach the relationship between the application of social governance and its role in improving the financial performance of economic institutions and their implications for sustainable development in the Egyptian private sector companies.

This is by summarized of problem search in the following questions:

- Is there a commitment to the rules of ESCG practices in private sector companies in Egypt?

- Is there an impact on compliance with the rules of ESCG in Egyptian private sector companies on their financial performance?

- What is the impact of the commitment to the rules of ESCG practices in the Egyptian private sector companies on the financial performance of these companies in the stock exchange?

\section{Research objectives}

The main objective of this study is to clarify and measure the impact of ESCG practices mechanisms on the financial performance of Egyptian private sector companies and their effect on the market value of these companies on the stock exchange.

Where the main objective is derived from the following objectives:

1. Determining the extent of compliance of the Egyptian private sector companies listed in the stock exchange to application of the rules of ESCG practices.

2. Determine the relationship between compliance with the rules environmental, of social governance and financial performance In the Egyptian private sector companies listed on the stock exchange.

3. Identify the impact of compliance with the rules of ESCG practices on the market value of the Egyptian private sector companies listed on the stock exchange.

\section{The importance of this study}

It is the subject of a new topic, where governance contributes to many of the economic aspects of raising the level of economic efficiency because of its importance in reducing the risks and build confidence between shareholders and protect their investments, and highlights the importance of this study to show the positive aspects of the application of social governance and its ability to improve the financial performance of Egyptian private sector companies As well as the impact of ESCG practices on the market value of Egyptian companies through the commitment of managers to implement them and the results that can be achieved individually and collectively in terms of leadership, effectiveness, performance and loyalty to the institution.

The success of the companies in their role in ESCG practices depends mainly on their commitment to three criteria:

- Respect and responsibility towards employees.

- Members of society.

- And support society and environmental protection.

Both in terms of commitment to the product consensus provided by the company to the community with the environment or in terms of initiative to provide the environment, improve environmental conditions in society and address various environmental problems. ESCG of the private sector is closely linked to the concept of "corporate governance» Which is considered one of the mechanisms of corporate governance

Although the application of ESCG practices to the private sector is a complex task, as it is a new concept in the region, these projects do not outweigh the capacity of companies operating in the region. They also benefit them and increase profitability.

The poor ESCG practices of businesses-the behaviour resulting from harmful effects on the environment and surrounding societyhas in many cases shown a direct negative impact on the financial performance of businesses. This was clearly demonstrated by the gap between the current and expected net profit before tax of these establishments, which reflects the reluctance of traders in the financial markets to buy those shares, which led to a decline in their market value [2].

There are some problems of methodological nature, which suffer from some businesses. Including the ambiguity of the nature of the integrative interdependence relationships within the enterprise, which can enable us to explain the causal pathways between the activities of the establishment and affect its financial and social performance.

Also of these problems is the lack of interest of business establishments to study the causes and consequences of business delays the negligence of businesses in preparing financial and social performance reports has resulted in incomplete reports, disingenuous and full of inaccuracies that do not reflect the actual performance or causes of the performance [3].

Hence, good social performance is useful to the business and not expensive, but on the contrary helps to strengthen financial performance, but not necessarily that the institution with good social performance also has a good financial performance, where there is another set of basic factors as mentioned and not should be omitted. Overall, there is undoubtedly a positive correlation between social performance and financial performance of business enterprises, where good social performance has been achieved that effectively increases the likelihood of good financial performance.

Institutions strive to achieve quality and excellence by promoting the application of concept ESCG practices, which in turn is reflected in the growth of society. It cannot achieve this without ethical standards that regulate the course of work, enhance trust between institutions and beneficiaries and are an important factor in the success of the 
relationship with the public, employees and other institutions. Moreover, the efforts of institutions to carry out ESCG practices often lead to increased efficiency and efficiency through improved working conditions and increased participation of staff in decision-making.

Thus, the researcher concludes from the previous analysis that the relationship between financial performance and social performance is positive, where good social performance helps to improve the image of the organization in front of society, as it is socially responsible to preserve the ethics and customs of the society and to preserve its environment and to support its sustainable development. These ethical and social principles-the principles of ESCG which seek good social performance to support them can be called impediments, the main objective of which is to try to prevent any social or moral losses from the establishment, which can adversely affect the financial performance of the establishment and cause financial losses.

The reminder of the paper is organized as follows. Section two literatures review and hypotheses development. Section three presents the study methodology. Section four describes data collection process, study variables and statistical techniques adopted. Section five discuses study findings. Section six concludes the study.

\section{Literature Review and Hypothesis Development}

\section{Previous studies}

In the 1960s and 1970s, the authors [4], in a direct response to the prevailing mood of philanthropy, said ESCG practices had a negative impact on the companyss financial performance, and that regulation and intervention from the «big government» would always hurt the macroeconomic. His claim that the valuation of the company or assets should be based almost exclusively on the final end result (with costs borne by ESCG practices deemed unnecessary), and confirms the prevailing belief in most of the twentieth century. By the end of the century, a conflicting theory was advancing. In 1988, Coleman [5] wrote In the American Journal of Sociology entitled «Social capital in the creation of human capital,» the article challenged the dominance of the concept of «self-interest» in the economy and introduced the concept of social capital in the measurement of value.

There was a form of pressure applied in an alliance with environmental groups and the investment power of its collective investors to encourage companies and capital markets to incorporate environmental and social challenges into daily decision-making. The Ceres Alliance today represents one of the most powerful investment groups in the world with more than 60 institutional investors from the US and Europe managing more than $\$ 4$ trillion of assets [6].

In the early years of the new millennium, the bulk of the investment market still accepts the historical assumption that morally oriented investments by nature are likely to reduce financial returns. Philanthropy was not known as highly profitable, and Friedman provided a widely accepted academic basis for the argument that the costs of acting in a morally responsible manner would outweigh the benefits. But the assumptions are beginning to face a fundamental challenge. In 1998, two journalists Robert Leving and Milton Moskovich [7] brought the Fortune 100 Companies to the fortune list, first in fortune magazine, followed by a book listing the best US companies in ESCG and how their financial performance. Some of the three areas of concern represented by the environmental and social group, the environment and socialism received the most attention from the public and the media, not least because of growing concerns about climate change. Moskowitz [7] highlighted the corporate governance aspect of responsible investment.
His analysis is about how companies are managed, how shareholders are treated and how employees are treated. Improving corporate governance did not harm financial performance; on the contrary, it maximized productivity, ensured the efficiency of companies and led to the utilization and utilization of senior management skills. In early 2000, the success of Muskowitz's list and its impact on company ease of employment and brand reputation began to challenge historical assumptions about the financial impact of EGG factors. In 2011, Alex Edmans [8] a Wharton financial professor, published a paper in the Financial Economics magazine showing that the top 100 companies outperform their peers in terms of stock returns by $2-3 \%$ per annum during the period 1984-2009, Analysts> expectations systematically [9].

Friedman provided academic support for the argument that the integration of factors into financial practice would reduce financial performance. Many reports began to emerge in the early years of the century, which provided research supporting arguments on the contrary. In 2006, Oxford University Michael Barnett and New York University Robert Salomon [10] published a very impressive study and concluded that both sides of the argument might be complementary they suggested a correlative relationship between ESCG and financial performance; non-selective investment practices could maximize financial performance. For an investment portfolio, the only way that can harm performance is the medium of selective investment [11]. In addition to large investment firms and banks dealing with the ISG issues, a group of investment companies that deal specifically with ASG-based investments has started to emerge across the financial world.

The development of environmental and social governance factors as considerations in investment analysis is now widely assumed by the investment industry to be inevitable [12]. Evidence supporting the relationship between performance in environmental management, social governance and financial performance issues is increasing, and the combination of credit duties and the broad recognition of longterm sustainability of investments mean that environmental and social concerns are becoming increasingly important in the investment market [13].

These factors are very similar to the immune system in the human body, which is its role in trying to prevent any diseases that may affect humans. Social performance of businesses, with its principles of ESCG, works to achieve an effective social and institutional framework that protects society from societal discontent and the discontent of stakeholders which may have a positive impact on the financial performance of the business, but not necessarily. In order to ensure good financial performance, not only preventative factors, which are aimed at achieving the social performance of enterprises, but must be combined with another set of factors affecting the directly on the financial performance of business enterprises, such as the various productive, marketing and financial policies adopted by the establishment, which are called motivator factors, which are essential factors and their existence is indispensable for achieving good financial performance, low cost and high revenues.

There are some studies that have used mathematical meta-analysis to find a relationship between some measures of social performance and financial performance of business enterprises, which have succeeded in finding a positive relationship between them. Of which analysed the results of 52 studies that tried to establish a relationship between financial performance and social performance of business enterprises, using different mathematical and statistical analysis methods to measure the effect of the results of the studies. This analysis took into 
account the possibility of sample corruption, error and unintentional measurement errors. The study concluded that there is a positive correlation between financial performance and social performance of enterprises through various studies, which were related to different industrial and commercial contexts [14].

In addition, it was found that the positive relationship varies between high positive and low positive according to various contingency factors such as reputations, market measures of financial performance or the extent of public social performance of enterprises (disclosure level) [15].

Another important study analysed the results of 167 studies on the relationship between financial and social performance of businesses, using the various statistical analysis methods to measure the impact of the results of the studies.

However, this statistical analysis was contrary to the previous study, which did not take into account the probability of corruption of the sample or the occurrence of any errors; on the contrary, it was based on the approach that equality between the results of the various studies in terms of quality, and the results of each study represent the voice at the evaluation and has approved the study of the existence of a positive relationship between the average financial performance and social performance of enterprises, especially since there is no evidence that the social performance is very expensive to reflect The results and all the evidence confirm that social irresponsibility-a bad societal behaviour-is very costly to business enterprises, which negatively affects their financial performance [16].

There are many studies that examined the relationship between the social behaviour of business establishments and their effect on the performance of their shares in the financial markets. One of the most prominent of these studies was the use of statistical analysis techniques to measure the reactions of financial markets to the irresponsible and illegal social practices of enterprises through twenty-seven case studies. He studies that examined share prices before and after these social practices were based on the definition of the practice as an act that the entity chose to do and which had a significant impact on stakeholder welfare.

The study focused on monitoring the impact of voluntary acts and social practices of enterprises, and excluded those resulting from government decisions and laws. The institution had to comply with them, despite the impact on financial markets such as government tax policies, and also excluded the impact of fatal accidents which can be exposed to the establishment, but did not exclude the reactions of the markets in case of tax evasion or violation of industrial and professional safety rules. Perhaps the full list of bad social practices observed by previous studies and their negative impact on stock prices in the capital market, and consequently the financial performance of the facility decreased, as follows: The production of products that do not conform to the health specifications, which represents a danger to the health of the consumer and destroy the trust of the customer in the products of the company, Price fixing, regardless of continuous market changes, commercial fraud, tax evasion, violation of environmental protection regulations, and contaminating pollution without work to maintain them [17].

Thus, the wealth of shareholders decreases as it increases the irresponsible social practices of business enterprises, this will have a negative impact on the shareholders confidence in dealing with this kind of poor social performance and push them to refrain from reducing their wealth.
Most of the studies that attempted to document a positive relationship between the good social performance of the business establishments and the financial performance achieved faced many problems, which were as follows:

Most managers ignore good social and moral performance by their employees And not to reward him or support him. The ethical behaviour that is responsible for these managers is that it does not produce harmful visual outcomes, and for them the absence of any harmful products may not necessarily be due to the good social performance of the employees, but may be due to luck, efficient management or even employees concern. Not to commit any mistake for fear of punishment.

Finally, much of the literature on the consequences of corporate social governance [18], responsibility has focused on analyzing the impact of ESCG on various [19], on the value of the company [20] on obtaining funding [21] and so on (post-audit) quality of financial reports with the general conclusion that ESCG affects all these dimensions but with mixed results.

\section{The definition of corporate environmental, Environmental and Social Corporate Governance practices}

The Egyptian economic institutions suffer from a number of problems, the majority of which are of an ethical nature centred on lack of trust, lack of transparency, lack of organizational culture of their own between internal and external parties or so-called "emerging parties» In the publication of social accounts and social security contributions, with the registration of some social campaigns associated with some religious events. Based on the above, the researcher has tried to address the concept of social governance and to emphasize its importance in establishing the moral principles of the institutions, in addition to their impact on financial performance and reflection on the sustainable development in the private sector companies in Egypt.

\section{Environmental and Social Corporate Governance practices theories}

Since the emergence of the term ESCG in 1953, many complex and unclear theories have emerged. Mele Ilisabet Garriga and Dominéc tried to explain these theories by distributing them to four groups [22].

The first group: Instrumental theories, through these theories the company is seen as a mere tool for creating value and social activity is only a means to reach economic results.

The second Group: Political theories, which deals with the relationship of politicians with the power of companies in society and the possibility of using this force in politics.

The third Group: Integrative theories, through which the company focuses on satisfying the needs of society

The fourth Group: Ethical theories, which focuses on the ethical responsibilities of the company towards society.

Even though ESCG practices have been an important issue among firms, investors and the public, there has been no standard definition of ESCG.

ESCG refers to 'the ability of a company to be socially responsible to the growth and development of the environment in which it operates.

ESCG practices are one of the foundations of the concept of "corporate governance». In the normal case, it is defined as: «the way 
the organization manages its economic, social and environmental activities», based on four dimensions:

\section{Economic prosperity}

2. The internal organization of the institution: This includes auditing and internal Control, transparency in transactions, and trust with the parties

3. Respect for the environment

4. Environmental and social relations.

The ESCG practices of the private sector in Egypt are very important as an important tool to ease the grip of globalization and its impact on the national economic system. As a result, attention to social governance has become essential to poverty reduction through the contribution of economic institutions (local companies or international institutions) to provide the right environment, not to waste resources, to carry out recruitment, training, human capacity development, and empowerment of women and to increase their capacities and skills to participate in the development process Weakness.

ESCG activities can be primarily targeted as a risk management strategy used by a company to enhance its reputation, which in turn protects the company from the risks of negative political, regulatory and social penalties. The lack of a positive corporate ESCG bias may result in negative penalties such as strong/political/media pressures, fines and possible penalties, and possibly boycotting consumers. In addition, positive participation in activities related to ESCG may lead to a range of financial benefits for the company. In fact, the common benefits to the positive involvement of ESCG may reduce the associated costs. Accordingly, companies can to some extent manage financial behaviour by increasing ESCG positive activities [23] to reduce the expected probability of falling into a state of financial distress.

The outcomes and impacts of actions and their impacts on the surrounding environment are the ultimate outcome of the social performance of the business. The measures of these outputs are very important, reflecting how much the business is benefiting or hurting stakeholder stakeholders, but society as a whole. The measures of these products and their effects are as follows:

1. Disclosure can be achieved if the business fulfils the statutory and legal requirements to comply with it, i.e., what is called public accountability, or through a particular response process, or tangible results that are realized and felt by various stakeholders. Transparency, disclosure and free circulation of information can be seen in more than one angle.

2. Stakeholder-specific measures

3. Stakeholders play four different roles that are consistent with efforts to measure the social performance of businesses and with efforts to find a relationship between financial performance and social performance of businesses in particular. These roles can be highlighted as follows:

Governance is one of the most widely recognized concepts of accounting and auditing. The researchers agreed that corporate governance is an investment that can provide a reason or success for companies by achieving value-sharing for different stakeholders. Which is the responsibility of many parties?

As mentioned before, social governance is one of the components of corporate governance, which is based mainly on the nature of the social relations between the different parties in the institution, whether internal or external, whether they are workers, managers, suppliers, customers. Therefore, economic institutions seeking to adopt the principles such as trust and citizenship to provide encouraging and favourable social relations for the performance of work, in other words the ability to "work together".

Friedman believes that the enterprise has a range of economic and financial concerns only, and therefore its social practices are to create the greatest financial value for shareholders and determines the responsibility of the institution towards the shareholders only and this by determining the roles of managers in the framework of the theory of the agency. In parallel, the managers had obligations towards their families, which led them to deduct part of their salaries and incomes as a result of their conviction of the reasons they see as valid and convincing. But in Friedman's view, these commitments and social feelings do not give managers the right to act on behalf of the owners in the realization of public social interests simply because they were seen as management experts. And not solve the problems of society. Was a special case in which managers were allowed to conduct social practices, in which case stockholders were assured that they would receive tax exemptions from the application of such practices?

There is a comprehensive concept of governance that goes beyond the material importance of profit and economic well-being of owners and managers to a lesser degree. There is also a common saying that if the institution is correct, it will correct the economy as a whole and if corrupt, its impact will extend to a number of economic sectors and society. Here is a comprehensive concept of governance that goes beyond the material importance of profit and economic well-being of owners and managers to a lesser degree.

In this direction, governance has an impact on individuals, institutions and society as a whole, providing individuals with a guarantee of a certain amount of profits and ensuring the stability and progress of markets. Therefore, we can say that institutions affect the environment and are affected by public life, especially at the level of jobs, incomes, savings and other matters that concern the lives of individuals and institutions together. Social governance extends to intersect with many economic, legal, social and economic fields. In terms of economics, the importance of governance is highlighted in that it works to ensure that financial performance is increased, that the organization>s funds are allocated and that its competitive position is strengthened by gaining the confidence of stakeholders in the market. To be conducive to attracting investments, whether local or foreign. In terms of law, lawmakers are concerned with social governance because they work to guarantee the rights of the various parties in the company because they work to guarantee the rights of different parties. Therefore, the legislations regulating the work of institutions are the backbone of the frameworks and mechanisms of corporate governance. Between the parties concerned in the enterprise (corporate laws, competition, taxes).

It is therefore possible to say that the importance of corporate governance in terms of law is reflected by overcoming the disadvantages of implementing contracts that may arise as a result of negative practices that violate contract formulas.

Therefore, the broader framework of social governance is not only related to the legal, financial and accounting aspects of institutions but is closely related to the economic, social and legal aspects, It can be said that if the company or institution is correct as the nucleus of the economy, and if it is corrupt, its impact can extend to a significant number of the economy and society as mentioned above. 
Citation: Elshawarby MA (2018) The Effect of Environmental and Social Corporate Governance on the Financial Performance with Special Focus on the Egyptian Private Sector Companies within Egx30. J Account Mark 7: 269. doi: 10.4172/2168-9601.1000269

\section{Mechanisms of Environmental and Social Corporate Governance}

Responsibilities of the board of directors: include the structure of the board and its legal duties, and how the selection of its members and its core functions, and its role in supervising executive management. The boards of directors are the link between those who provide the capital, and who have the most to lose, and those who are employed in order to manage and create value for the investors [24].

Disclosure and transparency: The disclosure of important information and the role of observer Accounts, disclosure of ownership of the majority of shares, and disclosure of members board of directors and Executives.

Disclosure and transparency are the most important elements of good corporate governance. Timely and accurate disclosure of all material matters relating to the companyss financial position, performance, ownership and governance are the elements of transparency in the company. Increased transparency will increase investor interest and build or restore confidence among stakeholders. This in turn increases access to external capital, improves operational performance, reduces internal risks and enhances confidence between senior management and the board of directors [25].

Protection of shareholders> rights: ESCG practices are the system of rules and responsibilities delegated to several groups within a corporation as well as procedures on handling corporate matters. One of the groups, shareholders, is given certain rights as owners of corporations. These rights are protected by law, and honouring them is one of the objectives in ESCG practices [26].

These include the transfer of ownership of shares, the selection of the board of directors, gain on profit, review of financial statements and the right of shareholders to participate effectively in meetings of the General Assembly.

Environmental and social governance towards the environment: In practice, after the stock market setback and associated disclosure of corporate greed, accepting the middle way, the recognition and involvement of the balance between private property, markets and state participation in the production of good environmental solutions to society is more likely today than it has been for many decades. Corporate managers, managers, people and governments play an important role in moving the agenda of effective corporate environmental management forward. Environmental accounting for managers is one of the tools that will be promoted in the corporate management toolkit [27]. Types of (ESCG) initiatives environment, water, soil and creatures. Its indicators are to link the environmental performance of the organization $>$ s mission with the reduction of environmental risks, the existence of environmental codes of ethics, the involvement of environmental representatives on the board, and incentives and incentives for those who excel in environmental activities.

Environmental and social governance towards consumers: An organization's survival depends largely on harmonious relationships with its stakeholders in the market. Customers provide the 'life-blood' to the organization in terms of competitive advantage, revenue and profits. Managing relationships with customers is imperative for all types and size of service organizations. A sound base of satisfied customers allows the organization to move on the path of growth, enhanced profitability, fight out competition and carve a niche in the market place [28].

It is the types of liability initiatives social-oriented and consumerdriven industrial enterprises, including products with reasonable prices, good quality, honest declaration, and safe products when use and clear instructions on the use and disposal of the product after use and the obligation to process post-sale damages.

Environmental and social governance towards society: One of the major challenges facing a number of Egyptian companies is how to promote social cohesion and combat social exclusion. Social exclusions threaten the peace and orderly development in Egypt. One of the tradition functions of environmental, social governance has been the creation of peace, good governance and orderly progress. The responsibility of industrial enterprises is about especially the community, to consider strengthening the relationship with the society as a positive view of the industrial institutions that initiate the strengthening of the relationship with this community. These indicators include support for infrastructure, respect for customs and traditions, non-violation of general rules and behaviour, fighting administrative corruption and bribery, scientific centres and educational institutions (Figure 1).

\section{Relationship between corporate governance and ESCG}

ESCG has become a major concern for business organizations in all developing and developed countries because of its direct and indirect

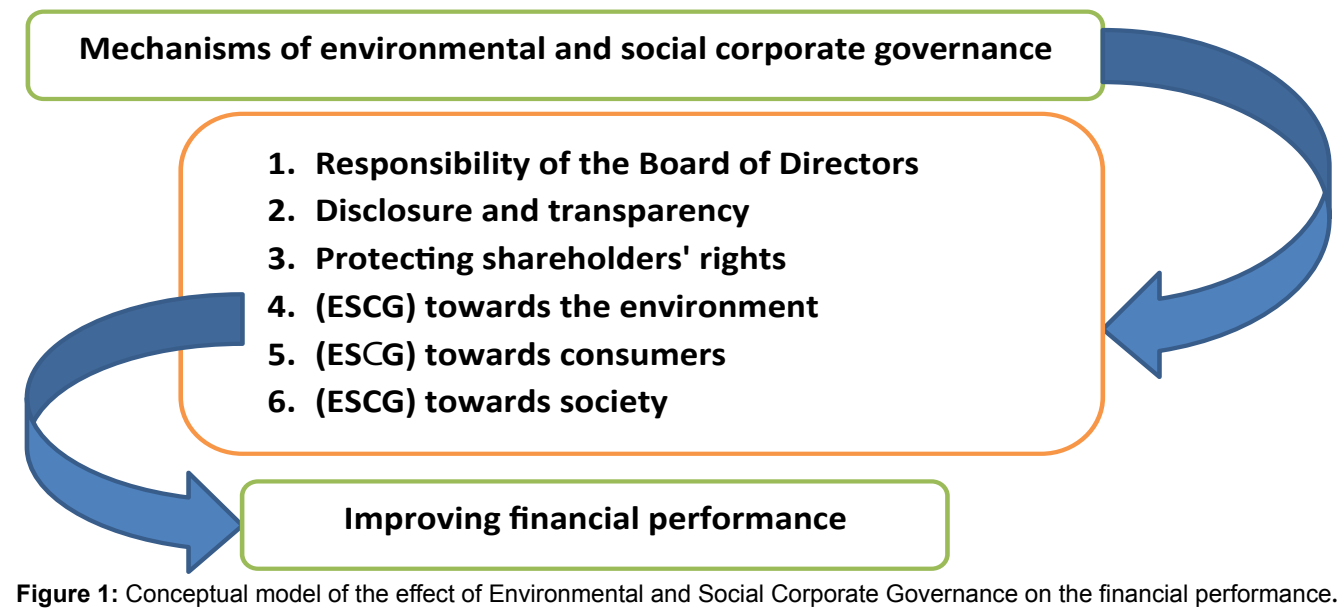


impact on the organization $s$ business and effectiveness. It has become one of the biggest challenges facing managers. Institutions have begun to demand the application of corporate governance to achieve stakeholder responsibility, ESCG towards their societies.

\section{ESCG: One of the most important foundations of corporate governance}

The recent collapse of large companies has led to efforts to preserve its reputation and the environment in which it operates, especially after scaling back confidence in these companies and governments enacting strict regulations. Many non-governmental organizations are also very frequent in the face of any mistakes made by institutions, in addition to the great pressure placed on these institutions by the procedures of classification and arrangement of advertising their non-financial performance and financial results, and the institutions are under control more than ever he went on. Contrary to what is rumoured that ESCG is a new trend, however, when studying the development of this concept, we note that, as it was common in America under the concept of «charitable work of institutions. In the first half of the twentieth century it became well known. To date, ESCG has not been specifically defined as gaining acceptance, there have been numerous initiatives in trying to define a precise definition of ESCG, and this difference is due to the nature of the environment surrounding the institution and the scope of its activity and capital. This responsibility is inherently dynamic, characterized by continuous development to suit the speed and requirements of the institution as well as the requirements of society according to economic, political and social changes.

There are many definitions of ESCG, including the following:

Terms of corporate environmental, social governance is a broad and complex concept with many definitions. In general, ESCG is a commercial contribution to sustainable development [29] by meeting the needs of the present without sacrificing the capacity to meet the needs of the future [30,31].

ESCG also allows companies to integrate their social and environmental responsibilities voluntarily into their business processes and interactions with stakeholders. It goes beyond the scope of legal compliance, and companies are encouraged to implement ESCG initiatives voluntarily to meet the different needs of stakeholders. Companies> participation in ESCG as a strategic marketing tool [32] gives them a competitive edge in the market that may make them more responsive to public expectations and meet their social and environmental responsibilities. As a result of these activities, companies develop a better overall image [33], which can help companies attract more customers [34] and improve employees [35].

Conversely, if companies do not realize value or benefits CESG, they may have a crippling attitude towards ESCG, their behaviour will not meet the publics expectations. These companies follow the argument of the authors [4] that the sole and sole goal of the business is to "maximize money while adhering to the basic rules of society.» Since CESG activities do not generate direct returns at times, their contributions are a misallocation of funds and may lead to objections from shareholders.

ESCG is the way the organization works, through which it integrates social, environmental and economic concerns and issues in the decision-making, strategies, policies, values, corporate culture, operations and activities within the organization with transparency and accountability to apply best practices, these projects are marketed to improve the image of the organization by making it ethical and increasing its credibility, thereby increasing its profits. But these differences do not prevent us from adopting a simple concept of ESCG, which can be considered as: «balanced integration of social and environmental considerations into the activities of the institution».

The idea of corporate environmental governance has emerged to provide a relationship with (cement) the three pillars of sustainable development-economic, environmental and social. Corporate governance has been defined as «Determining the responsibilities of the board of directors and determining the accountability of the board of directors to all stakeholders in the company (to include) the systems and tools used to achieve the companys environmental objectives and effectiveness in achieving the desired results».

With the development of the work environment of the institutions and with the increasing influence of the pressure forces, many approaches have emerged in the study of the content and types of ESCG, and we will address one of these approaches, which distinguish between three types of responsibility:

a) Economic responsibility: According to this trend (Milton Friedman), the institution must focus on the goal of maximizing profit, and that social contributions are only byproducts derived from it.

b) Social responsibility: This is the opposite of the first trend. The institutions consider social units to take into consideration society and its requirements during the decision-making process, despite the difficulties faced by economic institutions especially in developing countries in balancing social performance with economic performance.

c) Socio-economic responsibility: It is the most balanced type where institutions are considered not to represent only the interests of one side (owners), but to have relations with other parties called the emerging parties (State, civil society, parties).

In order to achieve a commitment to ESCG in the institutions, there is a need for a set of principles,

1. Respect for regulations (established by the institution) and laws (established by the state)

2. Recognition of stakeholders (emerging parties)

3. Transparency in transactions

4. Adoption of sustainable development

5. Commitment to business ethics

6. Working with the principles of human rights.

Reasons for non-compliance with corporate environmental, social governance ESCG in economic institutions. There are many reasons for the widespread application of corporate environmental, social governance ESCG in economic institutions, including:

1. Lack of a culture of ESCG at the institution: It is noticeable through studies interested in this subject that the number of institutions adopting this trend is few compared to the number of active institutions.

2. Lack of organization for the efforts of most institutions: ESCG of institutions to be effective, they need to take a structured organizational structure, based on a plan and has specific objectives. 
3. Lack of a culture of giving for development: Most of the efforts of institutions are limited to non-developmental work related to feeding the poor, providing clothing and others without moving towards development projects that radically change the standard of living of the poor.

4. Lack of experience: Especially lack of knowledge and scientific ability to set standards to measure efforts, and there is so far confusion between ESCG and charity due to lack of experience.

ESCG is characterized by several advantages, as mentioned above where corporate governance is responsible for ESCG and maintaining a clean environment for survival and development in the current economic environment. Changed the conditions of activity at the level of all markets and imposed new competitive conditions. A report released in April 2002 by the United Nations Environment Program (UNEP), the World Business Council for Sustainable Development and the World Resources Institute (WRI), entitled "Markets of Tomorrow: General Trends and their Impacts on Business" Economic, environmental and social indicators on the one hand, and the development of all markets on the other, in order to help institutions discover the future bets.

Environmental and Social Corporate Governance practices as the most important characteristics of corporate governance:

Corporate governance is characterized by a number of advantages, as mentioned above. Among these is ESCG, where corporate governance is responsible for ESCG and maintaining a clean environment, In order to survive and develop in the current economic environment, institutions must interact with social and environmental trends that have changed the conditions of activity at all markets and imposed new competitive conditions.

In order to survive and develop in the current economic environment, institutions must interact with social and environmental trends that have changed the conditions of activity at all markets and imposed new competitive conditions. A report released in April 2002 by the United Nations Environment Program (UNEP), the World Business Council for Sustainable Development and the World Resources Institute (WRI), entitled "Markets of Tomorrow: General Trends and Implications for Business", which linked indicators Economic, environmental and social aspects on the one hand, and the development of all markets on the other, in order to help institutions discover the future.

\section{The role of ESCG in improving the financial performance of Egyptian private sector companies}

ESCG plays an important role in improving the financial performance of Egyptian private sector companies through its mechanisms of (board responsibilities, disclosure and transparency, protecting shareholders' rights) where social governance helps institutions and the economy in general attract investments and support economic performance and competitiveness in the long run, through several methods, including:

By emphasizing the transparency of the corporation`s transactions and accounting procedures and financial audit, the governance is facing one of the two sides of the corruption relationship, which leads to the depletion of the resources of the institution, and the erosion of competitiveness, and therefore the departure of investors.

ESCG measures improve the management of the organization by helping managers and the board of directors develops a sound corporate strategy and ensures that decisions are taken on a sound basis, helping institutions attract investments on good terms.

In the relationship between ESCG and performance, accounting and financial thought have identified a number of factors through which ESCG can affect FP. These channels are the following

1. Increase access to external sources of finance, which in turn leads to investment opportunities Larger, higher growth, and higher employment use ratios.

2. Lower cost of capital associated with higher enterprise value, making investment more attractive for investors.

3. Better operational performance resulting from better resource allocation, which means better performance and greater value of wealth.

4. Reducing the risk of financial crises.

5. Better relationship with each of the stakeholders which helps to improve relations with community, employment and environmental protection.

Finally, the good application of the mechanisms of ESCG represents the way forward for individuals, institutions and society as a whole. This ensures that individuals have an appropriate level of guarantee to achieve reasonable profitability from their investments. These mechanisms ensure the strength and soundness of institutions> performance and thus strengthen and stabilize the progress of financial markets, economies and societies.

CESG has a significant and positive role in improving the performance of institutions and shows this from responsibility towards the environment, responsibility towards consumers, and responsibility towards society. Institutions that adopt the concept of CESG can achieve many benefits, including improving the relationship within institutions between management and employees on the one hand, and management and customers on the other. Image and reputation of enterprises and become able to attract investments, as well as improve the relationship between institutions and government for their benefit.

The commitment of institutions to environmental and social corporate governance programs has a positive impact on workers productivity and wage levels. Social governance activities result in cost savings, reduced turnover, lower penalties and fines, and reduced sentences against institutions that violate the law.

ESCG is the way the organization works, through which it integrates social, environmental and economic concerns and issues in the decision-making, strategies, policies, values, corporate culture, operations and activities within the organization with transparency and accountability to apply best practices, these projects are marketed to improve the image of the organization by making it ethical and increasing its credibility, thereby increasing its profits.But these differences do not prevent us from adopting a simple concept of ESCG, which can be considered as: «balanced integration of social and environmental considerations into the activities of the institution».

Social governance is characterized by several advantages, as mentioned above, including CESG, where corporate governance is responsible for ESCG and maintaining a clean environment for survival and development in the current economic environment. Changed the conditions of activity at the level of all markets and imposed new competitive conditions. A report released in April 2002 by the United Nations Environment Program (UNEP), the World Business Council 
Citation: Elshawarby MA (2018) The Effect of Environmental and Social Corporate Governance on the Financial Performance with Special Focus on the Egyptian Private Sector Companies within Egx30. J Account Mark 7: 269. doi: 10.4172/2168-9601.1000269

Page 9 of 12

for Sustainable Development and the World Resources Institute (WRI), entitled «Markets of Tomorrow: General trends and their Impacts on Business» economic, environmental and social indicators on the one hand, and the development of all markets on the other, in order to help institutions discover the future bets.

Economic responsibility as the most important characteristics of corporate governance: Corporate governance is characterized by a number of advantages, as mentioned above. Among these is ESCG, where corporate governance is responsible for ESCG and maintaining a clean environment, In order to survive and develop in the current economic environment, institutions must interact with social and environmental trends that have changed the conditions of activity at all markets and imposed new competitive conditions.

\section{Research Methodology}

The study utilized correlational research design as it sought to describe and establish the associations among the key study variables, namely, the ESCG and FP of Egyptian private sector companies within EGX30.

\section{Study variables and measurement indicators}

The basic variables in this study were determined in light of the nature of the problem, namely, the environmental and social corporate governance as an independent variable and financial performance as a dependent variable.

\section{Society and sample of the study}

The society of the study consists of all the industrial companies whose shares are traded in the Egyptian Stock Exchange during the period from 2016 to 2017. The number of companies till the end of 2016 is 30 companies distributed in economic sectors. Sample study according to the following conditions:

- Companies should be listed on the Egyptian Stock Exchange.

- The annual financial statements for the period from 2016 to 2017 are available in addition to the board of directors> report and the supplementary clarifications to complete the required data in the statistical models.

- Have not started and stopped activity during the study period.

Taking into account previous considerations, 30 companies were selected. The following table shows the number of sample companies classified by sector.

\section{Sources of data acquisition}

In order to obtain data, the researcher adopted the applied study on several sources

- What is available on the Egyptian Stock Exchange through its website from financial statements and reports.

- The annual disclosure book for the 50 companies issued by the Egyptian Stock Exchange, which includes the financial statements.

- The financial reports of some of the companies obtained from Misr for publishing information.

- Annual financial reports published by companies either through the company's website or the Egyptian Stock Exchange website.

\section{Study model}

The researcher relies on the formulation of research hypotheses on the model of simple regression, in order to measure the relationship between the ECSG and FP (Tables 1 and 2).

\section{Results and Discussions}

Results of testing hypotheses $\mathrm{H}$ : There is positive and significant relationship between the Environmental and social corporate governance and financial performance in Egyptian private sector companies.

Because the significant level is lower than $0.05, \mathrm{H} 1$ is confirmed. So, there is positive and significant relationship between the ESCG and FP in financial organizations and institutions. After calculating the correlation coefficient, we can also go to the simple linear regression and investigate correlation between two variables that regression coefficients and variance analysis are shown in Tables 3 and 4.

\begin{tabular}{|c|c|c|}
\hline ISIN code & Company name & Weight (\%) \\
\hline EGS60121C018 & Commercial International Bank (Egypt) & 38.95 \\
\hline EGS74081C018 & Global Telecom Holding & 8.01 \\
\hline EGS37091C013 & Eastern Company & 7.25 \\
\hline EGS69101C011 & $\begin{array}{c}\text { Egyptian Financial Group-Hermes Holding } \\
\text { Company }\end{array}$ & 5.95 \\
\hline EGS691S1C011 & T M G Holding & 4.91 \\
\hline EGS65571C019 & Medinet Nasr Housing & 4.04 \\
\hline EGS3G0Z1C014 & Elswedy electric & 3.61 \\
\hline EGS33041C012 & Oriental Weavers & 2.82 \\
\hline EGS380S1C017 & Sidi Kerir Petrochemicals & 2.60 \\
\hline EGS380P1C010 & Alexandria Mineral Oils Company & 2.56 \\
\hline EGS655L1C012 & Palm Hills Development Company & 2.52 \\
\hline EGS48031C016 & Telecom Egypt & 2.25 \\
\hline EGS65851C015 & $\begin{array}{l}\text { Six of October Development and Investment } \\
\text { (SODIC) }\end{array}$ & 2.13 \\
\hline EGS65591C017 & Heliopolis Housing & 1.89 \\
\hline EGS3C251C013 & Ezz Steel & 1.81 \\
\hline EGS691L1C018 & Pioneers Holding & 1.39 \\
\hline EGS693V1C014 & $\begin{array}{c}\text { Orascom Telecom Media And Technology } \\
\text { Holding }\end{array}$ & 0.88 \\
\hline EGS73541C012 & Citadel Capital-Common Shares & 0.86 \\
\hline EGS673Y1C015 & Emaar Misr for Development & 0.78 \\
\hline EGS32221C011 & Arab Cotton Ginning & 0.73 \\
\hline EGS694A1C018 & Porto Group & 0.63 \\
\hline EGS30031C016 & Arabian Food Industries DOMTY & 0.53 \\
\hline EGS70431C019 & Egyptian for Tourism Resorts & 0.52 \\
\hline EGS38381C017 & Egyptian Financial and Industrial & 0.47 \\
\hline EGS60111C019 & Abu Dhabi Islamic Bank-Egypt & 0.46 \\
\hline EGS675S1C011 & Amer Group Holding & 0.42 \\
\hline EGS3C001C016 & Arabian Cement Company & 0.40 \\
\hline EGS38201C017 & Egyptian Chemical Industries (Kima) & 0.34 \\
\hline EGS3D061C015 & Egyptian Iron and Steel & 0.22 \\
\hline EGS30581C010 & Cairo Oils and Soap & 0.07 \\
\hline
\end{tabular}

Table 1: EGX 30 index constituents' weights as of July 31.

\begin{tabular}{|c|c|c|}
\hline & Net profit before tax & Social governance \\
\hline Pearson Correlation & 1.000 & 0.856 \\
\hline Sig. (1-tailed) & & 0.000 \\
\hline N & 30 & 30 \\
\hline
\end{tabular}

Table 2: Correlation coefficient between delegation of authority to managers and financial performance. 
Citation: Elshawarby MA (2018) The Effect of Environmental and Social Corporate Governance on the Financial Performance with Special Focus on the Egyptian Private Sector Companies within Egx30. J Account Mark 7: 269. doi: 10.4172/2168-9601.1000269

Page 10 of 12

If the ESCG and financial institutions in Egyptian private sector companies show $\mathrm{X}$ and the financial performance show $\mathrm{Y}$, their relationship is expressed as follows:

\section{$\mathrm{Y}=0.228+13.396 \mathrm{X}$}

The last column of the above table shows that both factors (i.e., the intercept and slope) are significant. Increasing one more unit the ESCG, FP, 13.396 units become higher.

The Table 3 the overall situation in which the adjusted R Square model is the most important indicator. $\mathrm{R}$ square measured 0.723 . It shows the dependent variable explained by the independent variables. Amount of Dubin-Watson is used for investigation of independence of errors (the difference between the actual values and the values predicted by the regression equation). According to the value testing is between 1.5 or 2.5 , so H0 (no correlation between errors) will be accepted Table 5 .

\begin{tabular}{|c|c|c|c|c|c|c|}
\hline \multicolumn{2}{|c|}{ Model } & Sum of squares & df & Mean Square & F & Sig. \\
\hline \multirow{2}{*}{1} & Regression & 25.874 & 1 & 25.874 & 76.679 & $0.000^{\mathrm{b}}$ \\
\cline { 2 - 7 } & Residual & 9.448 & 28 & 0.337 & & \\
\hline & Total & 35.322 & 29 & & & \\
\hline
\end{tabular}

bPredictors: The environmental and social corporate governance (constant).

Table 3: Variance analysis between delegation of authority to managers and financial performance.

\begin{tabular}{|c|c|c|c|c|}
\hline \multirow{2}{*}{ Model } & Unstandardized coefficients & Standardized coefficients & Sig. \\
\cline { 2 - 4 } & B & Std. Error & Beta \\
\hline Constant & 0.228 & 0.118 & 1.943 \\
\hline The Environmental and Social Corporate Governance & 13.396 & 1.530 & 0.062 & 0.856 \\
\hline
\end{tabular}

Table 4: Regression coefficient between delegation of authority to managers and financial performance.

\begin{tabular}{|c|c|c|c|c|c|}
\hline Model & $\mathbf{R}$ & $\mathbf{R}$ Square & Adjusted R Square & Std. Error of the Estimate \\
\hline 1 & $0.856 a$ & 0.733 & 0.723 & 0.580888 \\
\hline
\end{tabular}

Table 5: Durbin-Watson test between social governance and financial performance in Egyptian private sector companies.

Histogram

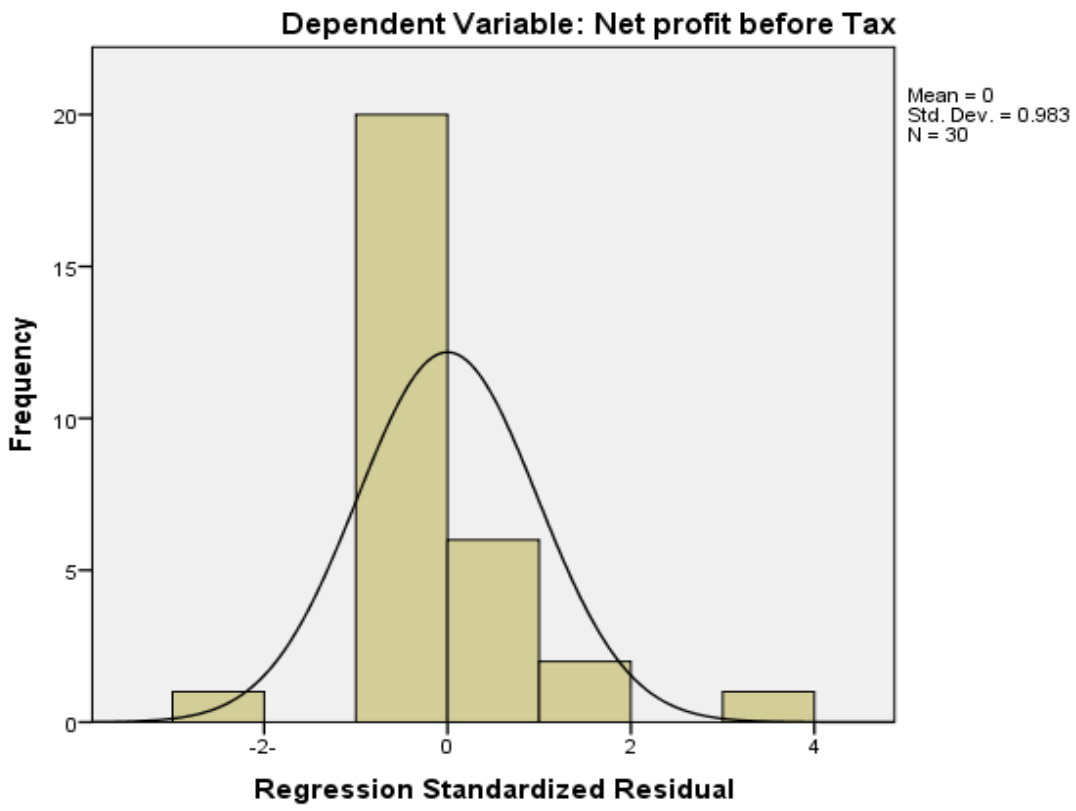

Figure 2: Conceptual model of regression standardized residual. 


\section{Normal P-P Plot of Regression Standardized Residual}

Dependent Variable: Net profit before Tax

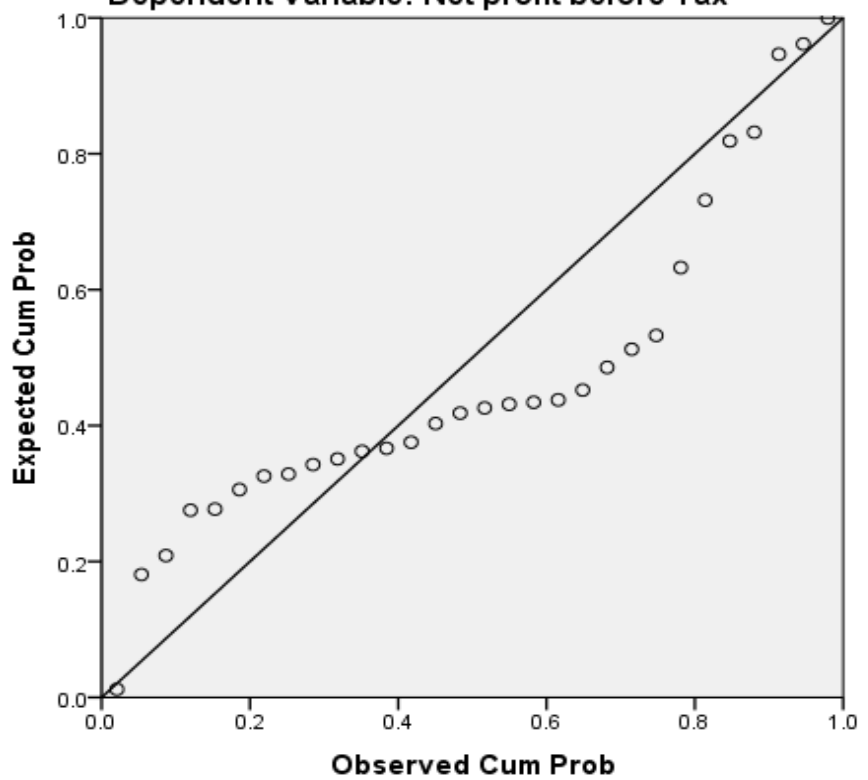

Figure 3: Conceptual model of observed cum Prob.

to application of the rules of ESCG practice and determine the relationship between compliance with the rules ESCG and FP In the Egyptian private sector companies listed on the stock exchange.

- The empirical results show that profitability is the major concern the Egyptian Stock Exchange -listed firms with respect to ESCG disclosure. Firms with more resources (e.g., profit) are more likely to issue ESCG reports, and issuing ESCG reports leads to a higher economic profit in the subsequent year. The findings indicate that the predominant factor determining CESG- initiatives is a company's profitability. As a golden rule, a business has to generate profit to cover its costs for survival and to provide funds for growth. For a business to maximize its profit, it must satisfy the needs of its stakeholders, particularly its customers. Therefore, companies do not undertake voluntary activities for altruistic reasons, but for their own selfinterests.

- The last Sub-goal is Identify the impact of compliance with the rules of ESCG practices on the market value of the Egyptian private sector companies listed on the stock exchange.

- This study finds significant positive association between CESG and market-related performance indicates that international CESG standards increase investors' confidence. Investors are more willing to invest in companies that follow international standards.

- These results suggest that one of the key profit drivers for companies with CESG can reduce social and environment costs and thereby increase corporate profit.

- The insignificant association of these two the ESCG and FP of Egyptian private sector companies within EGX30 suggests that the expenditure may be a reaction to international pressure.

In conclusion, in this paper we firstly aimed to show the significant effect of ESCG and FP of Egyptian private sector companies within EGX30. Hereby, with this study we accomplished our goal. We hoped that this study will be beneficial for Egyptian companies to improve good ESCG practices which in turn increase their firm performance.

\section{Future Directions for Research}

This study might be extended in various aspects and some possible ways are identified below.

Firstly, in this paper the time period was taken as 2016-2017. In order to be more accurate, this time period might be extended to more than 8 years. When it comes to the other direction, number of independent variables can be increased to be able to include most of the Environmental and social corporate governance indicators. Thirdly, since this study was concentrated only on Egypt, future research may include more than one country that is called as both developing and developed country. By including more than one country, ESCG practices and impacts of these countries can be displayed comparatively. Another recommendation for future research could be using primary data to have more reliable results. Lastly, in this paper, 30 companies from EGX30 Indexes were used as sampled data however future studies may make the analysis by using all companies in EGX indices to give a more reliable perspective and generalize the findings.

\section{References}

1. Godfrey PC, Merrill CB, Hansen JM (2009) The relationship between corporate social responsibility and shareholder value: An empirical test of the risk management hypothesis. Strategic Manage J 30: 425-445.

2. Wood DJ, Jones RE (1995) Stakeholder mismatching: A theoretical problem in empirical research on corporate social performance. The International Journal of Organizational Analysis 3: 229-267.

3. Wood DJ (2010) Measuring corporate social performance: A review. Int $J$ Manag Rev 12: 50-84.

4. Friedman M, Friedman R (1990) Free to choose: A personal statement Houghton Mifflin Harcourt. 
Citation: Elshawarby MA (2018) The Effect of Environmental and Social Corporate Governance on the Financial Performance with Special Focus on the Egyptian Private Sector Companies within Egx30. J Account Mark 7: 269. doi: 10.4172/2168-9601.1000269

5. Coleman JS (1988) Social capital in the creation of human capital. Am J Sociol 94.

6. Ceres (2003) Mobilizing business leadership for a sustainable world

7. Moskowitz M (1972) Choosing socially responsible stocks. Bus Soc Rev 1: 71-75.

8. Ballou B, Godwin NH, Shortridge RT (2003) Firm value and employee attitudes on workplace quality. Accounting Horizons 17: 329-341.

9. Edmans A (2011) Does the stock market fully value intangibles? Employee satisfaction and equity prices. J Financial Econ 101: 621-640.

10. Cogan DG (2003) Corporate governance and climate change: Making the connexion.

11. Barnett ML, Salomon RM (2006) Beyond dichotomy: The curvilinear relationship between social responsibility and financial performance. Strategic Management Journal 27: 1101-1122.

12. Invesco (2009) IPE European institutional asset management survey.

13. Aguilera RV, Williams CA, Conley JM, Rupp DE (2006) Corporate governance and social responsibility: A comparative analysis of the UK and the US. Corp Gov 14: 147-158.

14. Margolis JD, Elfenbein HA, Walsh JP (2007) Does it pay to be good? A metaanalysis and redirection of research on the relationship between corporate social and financial performance. Presentation at the Academy of Management Meetings, Philadelphia, PA.

15. Orlitzky M (2005) Social responsibility and financial performance: Trade-off or virtuous circle. University of Auckland Business Review 7: 37-43.

16. Margolis JD, Walsh JP (2003) Misery loves companies: Rethinking social initiatives by business. Adm Sci Q 48: 268-305

17. Frooman J (1997) Socially irresponsible and illegal behavior and shareholder wealth: A meta-analysis of event studies. Bus Soc 36: 221-249.

18. Eccles RG, loannou I, Serafeim G (2014) The impact of corporate sustainability on organizational processes and performance. Manag Sci 60: 2835-2857.

19. Di Giuli A, Kostovetsky L (2014) Are red or blue companies more likely to go green? Politics and corporate social responsibility. J Financial Econ 111: $158-180$.
20. Gregory A, Whittaker J, Yan X (2016) Corporate social performance competitive advantage, earnings persistence and firm value. J Bus Finance Account 43: 3-10.

21. Goss A, Roberts GS (2011) The impact of corporate (CESG) on the cost of bank loans. J Bank Finance 35: 1794-1810.

22. Garriga E, Melé D (2004) Corporate social responsibility theories: Mapping the territory. J Bus Ethics 53: 51-71.

23. Mugurusi G (2009) Corporate social responsibility: Is this Another Hoax?

24. Mary K. FCCA, Examiner in professional-1 corporate governance, the role of the board of directors in corporate governance, CPA Ireland.

25. Moses M (2017) Mwariri, Partner at FGC, the accountancy services company, corporate governance disclosure and transparency.

26. Rod Howell. The shareholder's rights in corporate governance.

27. UKEA (2003) United Kingdom Environment Agency.

28. Samwel NO (2013) The relationship between corporate governance and customer satisfaction among commercial banks in Kenya, University of Nairobi.

29. United Nation (2007) CESG and developing countries: Sustainable development. Innovation Brief.

30. The Institute of Chartered Accountants (2004) Information for better markets sustainability: The role of accountants. European Commission.

31. Qu R (2007) Corporate social responsibility in China: Impact of regulations market orientation and ownership structure. Chinese Management Studies 1 : 198-207.

32. Lancaster I (2004) Flavour of the month is here to stay as CESG takes firm hold in PR. Media Asia, pp: 1-3.

33. Ruf BM, Muralidhar K, Paul K (1998) The development of a systematic aggregate measure of corporate social performance. J Manag 24: 119-133.

34. Gatewood RD, Gowan MA, Lautenschlager GJ (1993) Corporate image, recruitment image and initial job choice decisions. Acad Manag J 36: 414-227.

35. Fischer J (2004) Social responsibility and ethics: clarifying the concepts. J Bus Ethics 52: 381-390. 